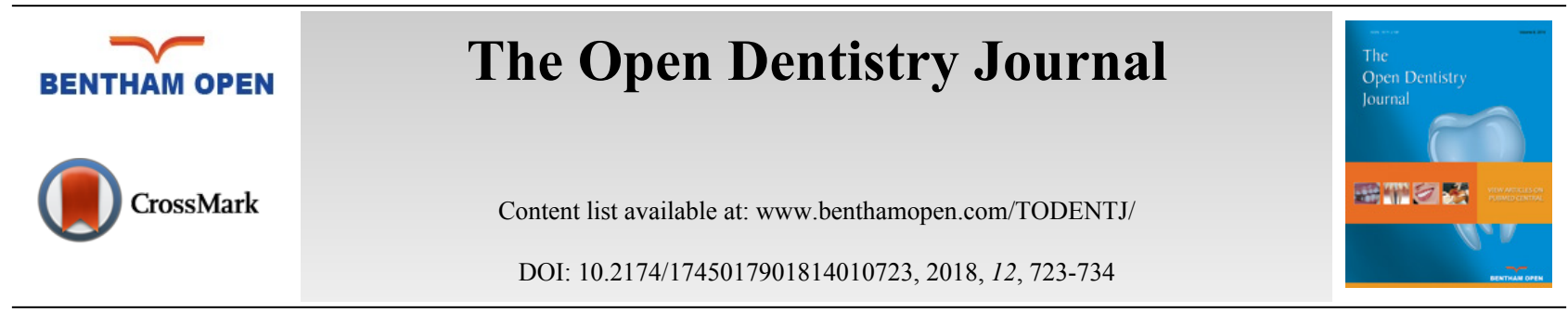

RESEARCH ARTICLE

\title{
Assessment of Masseter Muscle Appearance and Thickness in Edentulous and Dentate Patients by Ultrasonography
}

\author{
Meltem Mayil, Gaye Keser, Arzu Demir and Filiz Namdar Pekiner ${ }^{*}$ \\ Department of Oral and Maxillofacial Radiology, Marmara University, Faculty of Dentistry, Istanbul, Turkey
}

Received: April 30, 2018

Revised: July 18, 2018

Accepted: September 3, 2018

\begin{abstract}
:
Objectives:

The purpose of the present study was to examine ultrasonographic appearances of Masseter Muscle (MM) in dentate and edentulous patients without Temporomandibular Disorder (TMD).
\end{abstract}

\section{Materials and Methods:}

The thickness of the MM in 25 dentate (mean age: 30,68 $\pm 10,49$ ) and 24 edentulous (mean age: 61,46 \pm 9,71) patients, who visited routine dental examination, was measured at rest and at maximum contraction bilaterally. Examinations were performed using an Aloka Prosound $\alpha 6$ (Hitachi Aloka Medical Systems, Tokyo, Japan) equipped with an 8 MHz-wide bandwidth linear active matrix transducer (ranging from 1 to $15 \mathrm{MHz}$ ). The visibility and width of the internal echogenic bands of the MM were also assessed and the muscle appearance was classified as I of III types. Type I, characterized by the clear visibility of the fine bands; Type II, thickening echogenicity of the bands; Type III, disappearance or reduction in a number of the bands.

\section{Results:}

MM thickness at rest and contraction in the dentate group were significantly higher than the edentulous group $(p<0.05)$. Type I was the most common echogenic type in both dentate (right:16 (64\%), left; $15(60 \%)$ ) and edentulous patients (right; 22 (91.7\%), left; 18 $(75 \%))$. In a dentate group, type II was significantly higher than the edentulous group in both the right and left sides $(p<0.05 ; p$ $<0.01$, respectively). Age and gender seemed to have no significant effect on the echogenic type $(p>0.05)$.

\section{Conclusion:}

There were significant differences in the thickness at rest and contraction between the dentate and edentulous groups. It was clarified that ultrasonographic features of the MM in dentate and edentulous patients were different.

Keywords: Ultrasonographic appearances, Masseter muscle, Dentate group, Edentulous patients, Echogenic type, Temporomandibular disorder.

\section{INTRODUCTION}

Relationships between edentulism, temporomandibular joint, musculature and the nervous system are important. The symmetry of muscle size on the right and left side and morphology within each individual are significant when the literature is reviewed. A broad range of factors, such as skeletal size, age, masticatory habits and general health are related to variation between individuals [1 - 4].

Changes in the muscle fiber size and composition, which in turn will increase the strength of the muscle and the resistance to fatigue may be a result of intensive use of any skeletal muscle. This is also relevant for the masticatory

\footnotetext{
* Address correspondence to this author at the Department of Oral and Maxillofacial Radiology, Marmara University, Faculty of Dentistry, Istanbul, Turkey; Tel: +90 02164211621 ; E-mail: fpekiner@gmail.com
} 
muscles. Therefore, it could be expected that this prolonged bilateral difference in the activity level of the masticatory muscles may work as an asymmetric training stimulation which results in differences in the thickness of the muscles. However, the masticatory muscles are also involved in functions that are not necessarily related only to mastication, and it is unknown that if previously observed bilateral differences in the activity level of the masticatory muscles are enough to create detectable changes in the muscle thickness [5 - 8].

A negative impact on the macro- and microscopic structure of the chewing muscles is observed with the patient's age and years of the edentulism [9]. Radiographic density and the cross-sectional area of the masseter and medial pterygoid muscle decrease with age and these effects are significantly provoked by edentulism [10]. The masseter muscle is one of the dominant muscles that provide the force necessary to chew efficiently. Mastication can occur bilaterally, yet $78 \%$ of observed subjects have a preferred side where the majority of chewing occurs. This is generally the side with the greatest number of tooth contacts during lateral glide $[11,12]$.

Unilateral partial edentulous subjects mostly use the dentate side, and this is where the majority of the chewing occurs [13]. The weight of the masseter muscle was significantly reduced in a study by Urushiyama et al. [14]' where the change was made from a hard to a soft texture diet in an animal model. Mice fed with a soft diet lost $19 \%$ of the muscle weight within 1 week. For complete denture wearers who often compensate for the lack of masticatory ability by changing to a softer diet, these findings are particularly relevant [15]. The observed atrophy of the muscle tissues in edentulous patients with conventional complete dentures may, therefore, be caused by a "de-training" effect.

Masseter (MM) is a thick, quadrilateral muscle, consisting of superficial and deep portions. The superficial portion, the larger area, arises with tendinous aponeurosis from the zygomatic process of maxilla and its fibers pass downward and backward attaches lateral surface of the ramus of mandible. The deep portion is much smaller and arises from the posterior lower border of the zygomatic arch; and its fibers pass downward and forward, to attach onto the upper half of the ramus and coronoid process $[3,16,17]$.

With various imaging techniques including ultrasound scanning, Computerized Tomography (CT) and Magnetic Resonance İmaging (MRI), masseter muscle thickness has been measured. Ultrasound imaging (US) is particularly suitable for imaging superficial structures of the head and neck region. It is appropriate for larger scale studies, due to its numerous advantages comparing to CT and MRI [18]. Without the use of ionizing radiation, US allows an economical method to measure muscle thickness [18 - 22]. Also, the ultrasound equipment is accurate for soft tissues assessment $[21,23]$. Therefore, US is a simple technique with a rapid diagnosis, non-invasive and does not use ionizing radiation. This technique allows the clinician to measure accurately the thickness of the masseter muscle [20, 21,24]. As a choice of US in determining the MM thickness was guided by the recommendations of previous studies, which described reliability, accuracy and advantages of the ultrasound methods comparing with MRI and CT [19, 20, 22,25].

The purpose of this study was to assess the masseter muscle appearance and thicknesses while the teeth were occluding relaxed and contracted during maximal clenching in dentate healthy subjects and in edentulous patients by ultrasonography. In addition, the effect of age and gender on muscle appearance and thickness in the two group were evaluated.

\section{MATERIALS AND METHODS}

Twenty-five dentate (13 female, 12 male) and twenty- four (12 female, 12 male) edentulous patients without TMD were enrolled in this study. The age range was from 22 to 55 (mean: 30,68土10,49) for the dentate group and from 41 to 81 (mean: 61,46 $\pm 9,71$ ) years old for the edentulous group. All subjects were continuously selected from patients who visited Marmara University, Faculty of Dentistry, Department of Oral Diagnosis and Radiology for several complaints. The edentulous patients were selected as missing all teeth and wearing a complete dental prosthesis at least five years, the dentate patients were selected as missing no teeth in their mouth. The patients were selected on the basis of the following criteria: (1) no bony changes that effect masticatory muscle function on conventional radiographs of maxilla, mandible and TMJ region (2) no history of masticatory muscle pain at least 3 months or more before they visited our clinic; (3) no pain with palpation on masticatory muscle during clinical examination (4) no deviation or limitation while mouth opening (5) no disease which affects muscle structure (submucous fibrosis, dermatomyositis, myasthenia gravis... etc). The study protocol numbered as 09.2015 .129 was approved by Non-invasive Clinical Research Ethics Committee, Marmara University Faculty of Medicine. The patients were informed about the study procedure and informed consent was received. 
Each patient was seated in an upright position with the head in the natural position. At first, the patients were asked to be relaxed and MM thicknesses were measured bilaterally. At the second stage, the patient was asked to clench their teeth and MM thicknesses were measured again bilaterally. The measurements for each group were obtained from the thickest part of MM. The thickness was defined as the maximal distance between the outer fascia of the muscle and the lateral surface of the ramus. While doing measurements, both sides of the masseter muscle were scanned perpendicular to the anterior border of the muscle and the surface of the mandibular ramus at approximately $2.5 \mathrm{~cm}$ above the inferior border of the mandible with minimum pressure to obtain the muscle image as thick as possible (Fig. 1). Examinations were performed by using an Aloka Prosound $\alpha 6$ (Hitachi Aloka Medical Systems, Tokyo, Japan) equipped with an 8 $\mathrm{MHz}$-wide bandwidth linear active matrix transducer (ranging from 1 to $15 \mathrm{MHz}$ ). The ultrasonograms were obtained with MM mode and an image depth of $3.5 \mathrm{~cm}$, echo gain was 80-90 dB. After thickness measurement, the appearance of MM was also assessed by considering visibility and width of the internal echogenic bands and the muscle appearance were classified into three types.

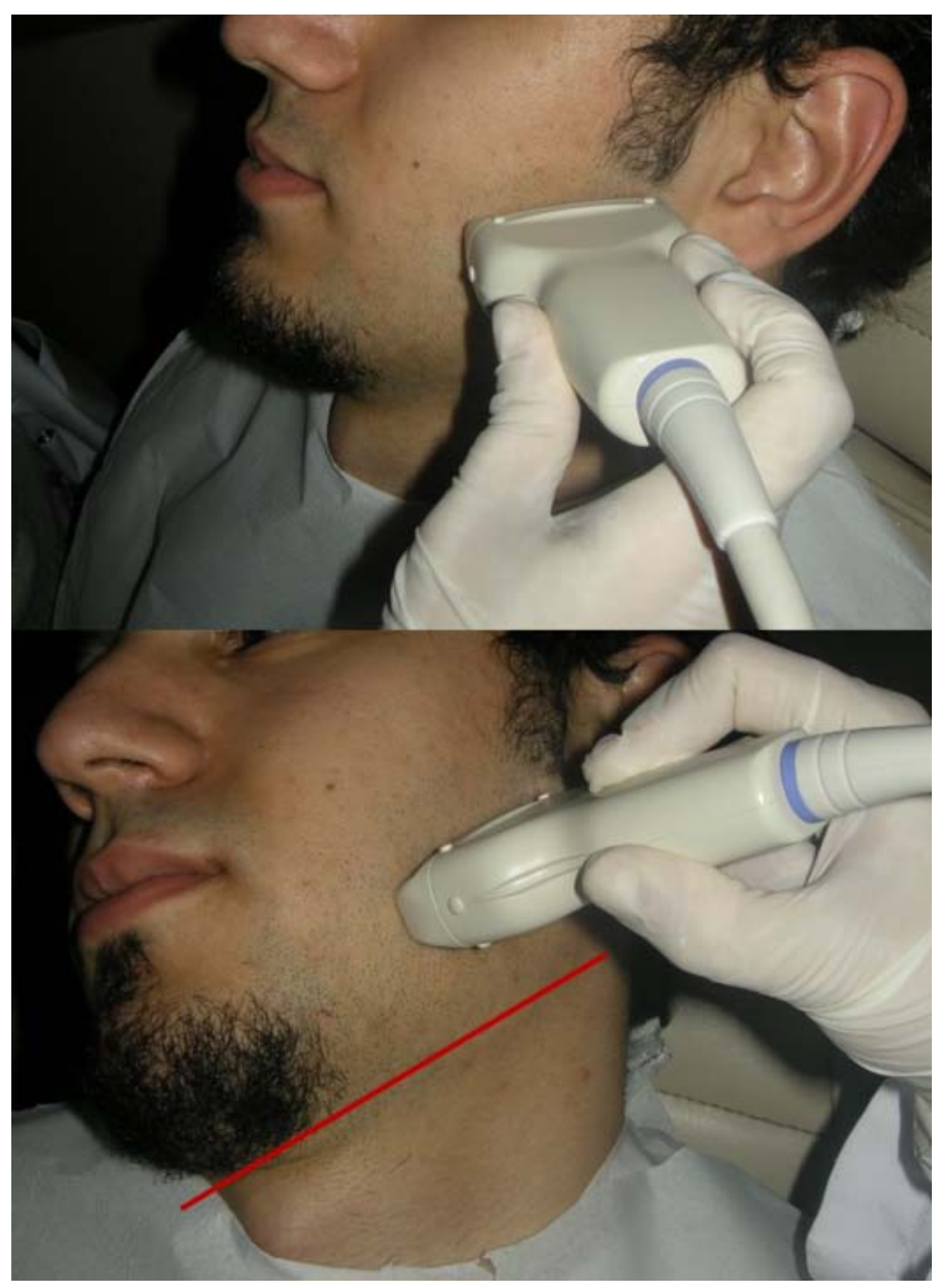

Fig. (1). US examination of MM with the transducer positioned perpendicular to muscle surface and aproximately $2.5 \mathrm{~cm}$ above the inferior border of mandible (The red line shows the inferior border of mandible). 
Type I: Characterized by the clear visibility of the transverse fine bands at the middle depth of the muscle (Fig. 2)

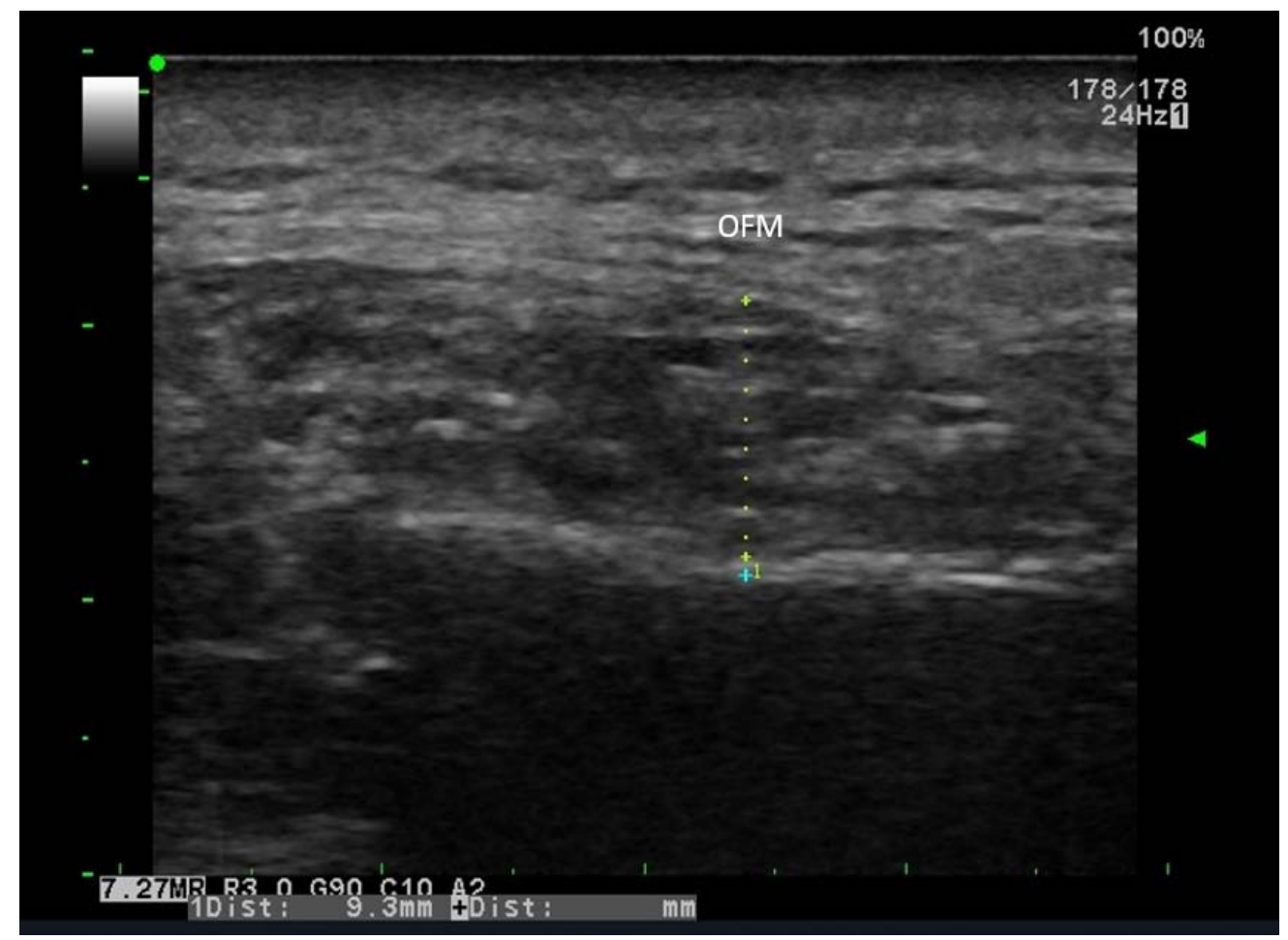

Fig. (2). Measurement of MM thickness from the Outer Fascia of the Masseter Muscle (OFM) to the Lateral Surface of the Ramus (LSM) and evaluation of internal sonotype I; characterized by the clear visibility of the fine bands.

Type II: Thickening and the weakened echogenicity of the transverse fine bands and several short bands (Fig. 3)

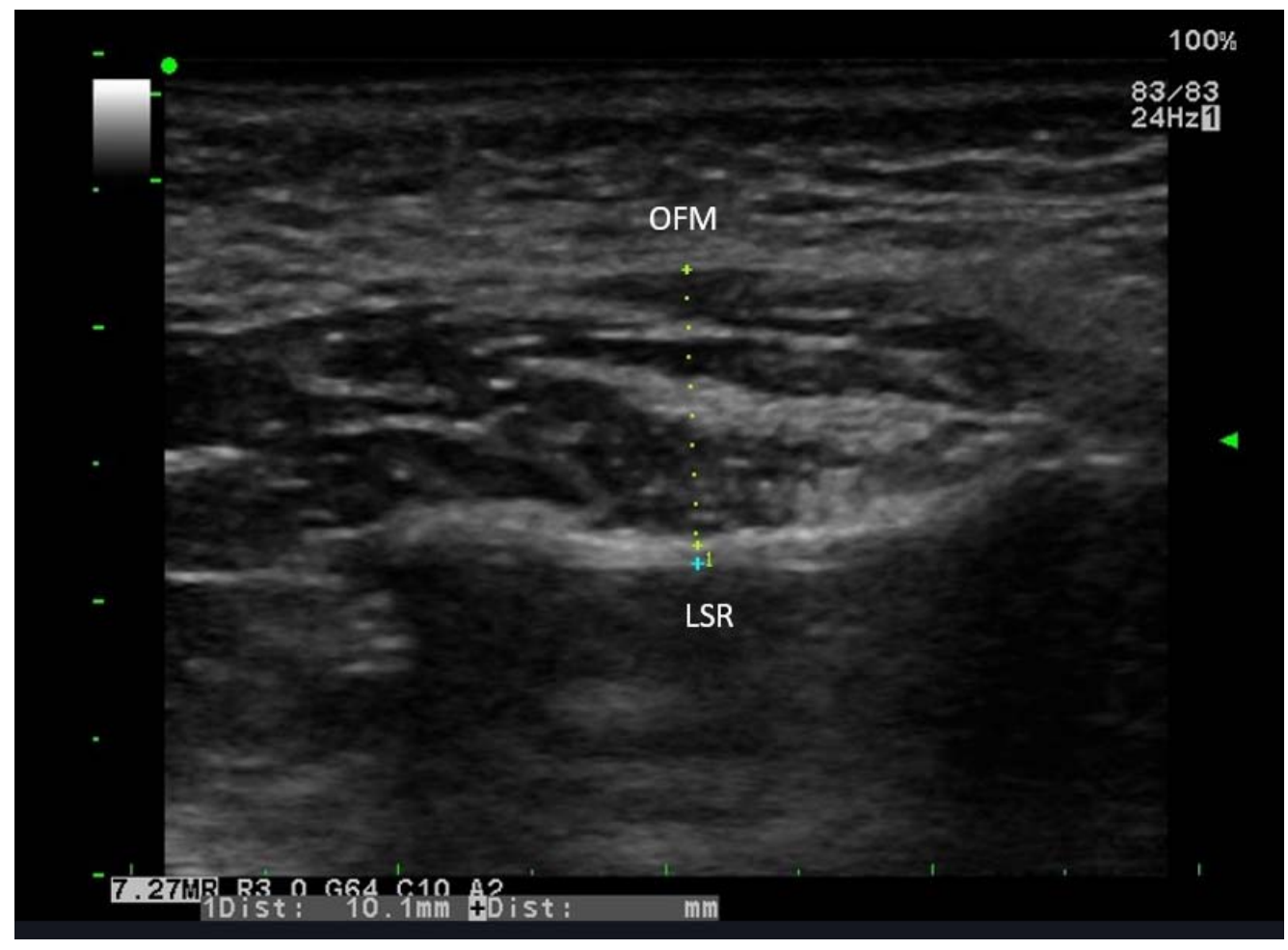

Fig. (3). Measurement of MM thickness from the Outer Fascia of the Muscle (OFM) to the Lateral Surface of the Ramus (LSR) and evaluation of internal sonotype II; characterized by thickening echo-intensity echogenicity of the bands. 
Type III: Disappearance or reduction in a number of the several short bands without a transverse band ( Fig. 4).

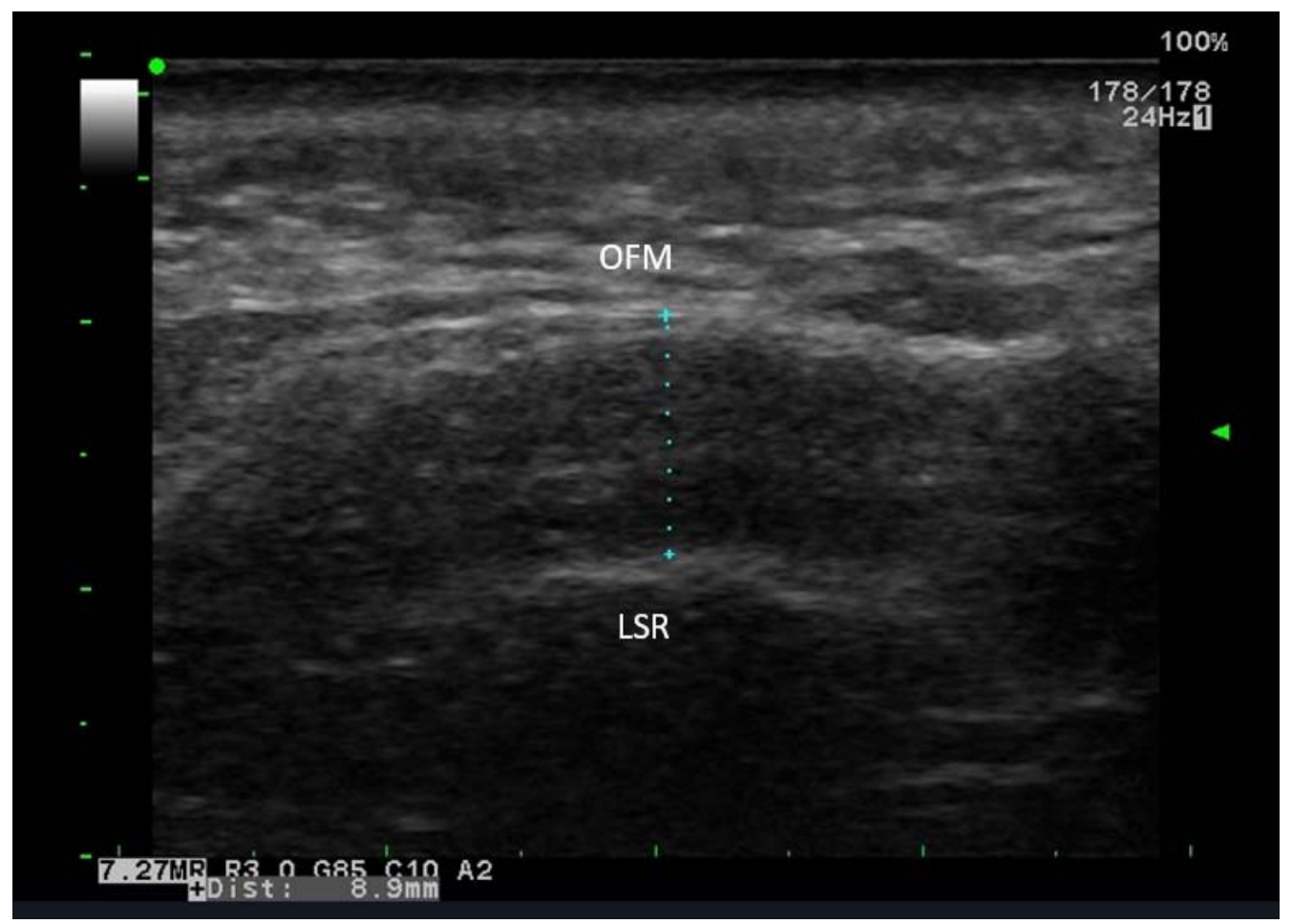

Fig. (4). Measurement of MM thickness from the outer fascia of the masseter muscle (OFM) to the lateral surface of the ramus (LSR) and evaluation of internal sonotype III; characterized by disappearance or reduction in number of the bands.

All of the evaluation and measurements were performed by three clinicians together (M.M., G.K., and A.D.), who had sufficient experience in the interpretation of ultrasonography. The clinicians had been trained and calibrated by a specialist who has been working in Oral Diagnosis and Radiology for fifteen years (F.N.P). Calibration trials were performed initially to ensure an inter-examiner consistency of at least $85 \%$ in the recording. For calibration, 12 patients were evaluated and not included in the main study. The inter-examiner agreement was measured by Cohen's Kappa statistic.

\subsection{Statistical Analysis}

All analyses were performed in IBM SPSS Statistics 22 (IBM SPSS, Turkey) environment. The student t-test was used for comparison of descriptive statistics (mean, standard deviation) and quantitative data with normal distribution between two groups. Mann Whitney U test was used for parameters showing abnormal distribution between 2 groups. Kruskal Wallis test was used for the comparison between the groups of parameters that were not normally distributed. The Chi-squared test, Fisher's exact chi-squared test and Continuity (Yates) correction were used for comparing qualitative data. $p<0.05$ was accepted for as significance level.

\section{RESULTS}

The mean age of patients was $30,68 \pm 10,49$ for the dentate group and $61,46 \pm 9,71$ for the edentulous patients. The mean age of the dentate group was significantly lower than the edentulous group $(p<0.01)$.

The means of MM thicknesses for each group at rest and contraction stages are seen in Table 1. The means of right MM thicknesses of dentate group at rest and at contraction were higher than the edentulous group $(p<0.01)$. The means of left MM thicknesses of dentate group at rest and contraction were also higher than edentulous group $(p<0.05 ; p$ $<0.01)$.

The means of increases of MM thicknesses while passing from rest to contraction stage are seen in Table $\mathbf{1}$ for each group. This increase was statistically significant within the groups $(p<0.01)$ but a comparison of increases among the groups were not $(p>0.05)$. 
Table 1. Comparision of MM thickess of dentate and edentulous group.

\begin{tabular}{|c|c|c|c|}
\hline \multirow{2}{*}{-} & Dentate & Edentulous & \multirow{2}{*}{$p$} \\
\hline & Mean \pm SD & Mean \pm SD & \\
\hline Right & - & - & - \\
\hline Relaxed & $11,58 \pm 2,18$ & $9,43 \pm 1,98$ & 10,001 ** \\
\hline Contracted & $13,36 \pm 2,31$ & $10,81 \pm 1,49$ & 10,001 ** \\
\hline Difference & $1,78 \pm 1,2(1,8)$ & $1,38 \pm 1,45(1,65)$ & ${ }^{2} 0,617$ \\
\hline${ }^{3} p$ & $0,001 * *$ & $0,001 * *$ & - \\
\hline Left & - & - & - \\
\hline Relaxed & $10,58 \pm 1,66$ & $9,37 \pm 1,82$ & ${ }^{1} 0,019 *$ \\
\hline Contracted & $12,81 \pm 1,85$ & $10,74 \pm 2,06$ & 10,001 ** \\
\hline Difference & $1,23 \pm 2,06(1,2)$ & $1,32 \pm 2,38(1,45)$ & ${ }^{2} 0,818$ \\
\hline${ }^{3} p$ & $0,001 * *$ & $0,001 * *$ & - \\
\hline
\end{tabular}

${ }^{1}$ Student $\mathrm{t}$ Test ${ }^{2}$ Mann Whitney U Test ${ }^{3}$ Paired $\mathrm{t}$ Test ${ }^{* *} p<0.01{ }^{*} p<0.05$

In dentate and edentulous groups, no significant relationship was found between age and both relaxed MM thickness and contracted MM thickness $(p>0.05)$ (Table 2).

Table 2. Corelation of MM thickness with age in dentate and edentulous groups.

\begin{tabular}{|c|c|c|}
\hline \multirow{2}{*}{-} & \multicolumn{2}{|c|}{ Age } \\
\cline { 2 - 3 } & \multicolumn{2}{|c|}{$\boldsymbol{p}$} \\
\hline Dentate & - & - \\
\hline Right Relaxed & 0,075 & 0,721 \\
\hline Left Relaxed & $-0,047$ & 0,822 \\
\hline Right Contracted & $-0,166$ & 0,428 \\
\hline Left Contracted & $-0,171$ & 0,414 \\
\hline Edentulous & - & - \\
\hline Right Relaxed & 0,219 & 0,304 \\
\hline Left Relaxed & 0,241 & 0,256 \\
\hline Right Contracted & 0,150 & 0,625 \\
\hline Left Contracted & 0,178 & 0,406 \\
\hline
\end{tabular}

Pearson Correlation

In a dentate group, the means of right MM thicknesses at rest and contraction were higher in male than female ( $p$ $<0.05)$. On the left side, the mean of MM thicknesses at rest was higher in male than female $(p: 0.049 ; p<0.05)$ but there was no significant difference at contraction stage $(p>0.05)$. Among males and females, there was no significant difference between the means of increases of MM thicknesses while passing from rest to contraction stage $(p>0.05)$ both on left and right sides (Table 3 ).

Table 3. Evaluation of effect of gender on MM thickness in gropus.

\begin{tabular}{|c|c|c|c|c|}
\hline & \multirow{2}{*}{-} & Female & Male & \multirow[b]{2}{*}{$p$} \\
\hline & & Mean \pm SD (Median) & Mean \pm SD (Median) & \\
\hline \multirow{10}{*}{ Dentate } & Right & - & - & - \\
\hline & Relaxed & $10,67 \pm 1,94$ & $12,57 \pm 2,05$ & ${ }^{1} 0,026 *$ \\
\hline & Contracted & $12,42 \pm 1,83$ & $14,39 \pm 2,4$ & 19,029* \\
\hline & Difference & $1,75 \pm 1,48(1,7)$ & $1,83 \pm 0,86(1,85)$ & ${ }^{2} 0,428$ \\
\hline & ${ }^{3} p$ & $0,001 * *$ & $0,001 * *$ & - \\
\hline & Left & - & - & - \\
\hline & Relaxed & $9,97 \pm 1,71$ & $11,24 \pm 1,38$ & $10,049 *$ \\
\hline & Contracted & $12,52 \pm 1,73$ & $13,13 \pm 1,99$ & ${ }^{1} 0,427$ \\
\hline & Difference & $1,85 \pm 1,82(1,7)$ & $0,56 \pm 2,18(0,7)$ & ${ }^{2} 0,173$ \\
\hline & ${ }^{3} p$ & $0,001 * *$ & $0,003 * *$ & - \\
\hline
\end{tabular}


(Table 3) contd.....

\begin{tabular}{|c|c|c|c|c|}
\hline & \multirow{2}{*}{-} & Female & Male & \multirow{2}{*}{$p$} \\
\hline & & Mean \pm SD $($ Median) & Mean \pm SD $($ Median) & \\
\hline \multirow{10}{*}{ Edentulous } & Right & - & - & - \\
\hline & Relaxed & $9,2 \pm 2,18$ & $9,65 \pm 1,82$ & 10,589 \\
\hline & Contracted & $10,28 \pm 1,31$ & $11,34 \pm 1,53$ & ${ }^{1} \mathbf{0 , 0 7 9}$ \\
\hline & Difference & $1,08 \pm 1,5(1,15)$ & $1,69 \pm 1,38(1,9)$ & ${ }^{2} 0,285$ \\
\hline & ${ }^{3} p$ & $0,031 *$ & $0,001 * *$ & - \\
\hline & Left & - & - & - \\
\hline & Relaxed & $8,93 \pm 1,85$ & $9,8 \pm 1,76$ & ${ }^{1} 0,252$ \\
\hline & Contracted & $10,23 \pm 1,5$ & $11,26 \pm 2,46$ & ${ }^{1} \mathbf{0 , 2 2 7}$ \\
\hline & Differrence & $1,03 \pm 2,31(1,45)$ & $1,61 \pm 2,52(1,75)$ & ${ }^{2} 0,729$ \\
\hline & ${ }^{3} p$ & $0,006 * *$ & $0,004 * *$ & - \\
\hline
\end{tabular}

${ }^{1}$ Student $\mathrm{t}$ Test ${ }^{2}$ Mann Whitney U Test ${ }^{3}$ Paired t Test $* * p<0.01 * p<0.05$

In an edentulous group, both on left and right sides among the genders, there was no significant difference between means of right $\mathrm{MM}$ thicknesses at rest and contraction $(p>0.05)$. Among males and females, there was no significant difference between the means of increases of MM thicknesses while passing from rest to contraction stage $(p>0.05)$ on both left and right sides (Table 3 ).

Type I was the most common band echogenicity type in the dentate group for both left (\%60) and right (\% 64) sides, also in edentulous group for both left (75\%) and right $(91.7 \%)$ sides. There was a statistically significant difference on the right side according to band echogenicity type between dentate and edentulous groups $(p<0.05)$. On the right side in dentate group (24\%), band echogenicity Type II rate was significantly higher than edentulous group $(0 \%)(p<0.05)$. Type I rate in dentate group $(64 \%)$ was significantly lower than edentulous group $(91.7 \%)$ on the right side (Table 4).

Table 4. Evaluation of dentate and edentulous groups according to the muscle appearance.

\begin{tabular}{|c|c|c|c|}
\hline \multirow{2}{*}{-} & Dentate & Edentulous & \multirow{2}{*}{$p$} \\
\hline & n (\%) & n (\%) & \\
\hline Right & - & - & - \\
\hline $\begin{array}{c}\text { Type I } \\
\text { Type II }\end{array}$ & $\begin{array}{c}16(64 \%) \\
6(24 \%) \\
\end{array}$ & $\begin{array}{c}22(91,7 \%) \\
0(0 \%) \\
\end{array}$ & \multirow[t]{2}{*}{$0,028 *$} \\
\hline Type III & $3(12 \%)$ & $2(8,3 \%)$ & \\
\hline Left & - & - & - \\
\hline $\begin{array}{c}\text { Type I } \\
\text { Type II }\end{array}$ & $\begin{array}{c}15(60 \%) \\
8(32 \%)\end{array}$ & $\begin{array}{c}18(75 \%) \\
0(0 \%)\end{array}$ & \multirow[t]{2}{*}{$0,006 *$} \\
\hline Type III & $2(8 \%)$ & $6(25 \%)$ & \\
\hline
\end{tabular}

Chi-square Test $* * p<0.01 * p<0.05$

There was also a statistically significant difference on the left side according to the muscle appearance between dentate and edentulous groups $(p<0.01)$. The origin of the significance was same as on the right side, that band echogenicity Type II rate in the dentate group (32\%) was significantly higher than edentulous group ( $0 \%)$ on left side $(p$ $<0.01)$. A statistically significant difference was not found between I and III band echogenicity types in dentate and edentulous groups on the left side $(p>0.05)$ (Table 5).

Table 5. Evaluation of effect of age on the muscle appearance in groups.

\begin{tabular}{|c|c|c|c|c|c|}
\hline & \multirow{3}{*}{-} & \multicolumn{3}{|c|}{ Age } & \multirow{3}{*}{$p$} \\
\hline & & \multirow{2}{*}{$\frac{\text { III }}{\text { Mean } \pm S}$} & II & \multirow{2}{*}{$\frac{\text { I }}{\text { Mean } \pm \text { SD }}$} & \\
\hline & & & & & \\
\hline \multirow{2}{*}{ Right } & Dentate & $35 \pm 17,44(27)$ & $34 \pm 12,2(30)$ & $55(24,5)$ & 10,572 \\
\hline & Edentulous & $52 \pm 15,56(52)$ & - & $08(62,5)$ & ${ }^{2} 0,250$ \\
\hline \multirow{2}{*}{ Left } & Dentate & $41,5 \pm 19,1(41,5)$ & $33,13 \pm 10,6(30)$ & $84(24)$ & 0,110 \\
\hline & Edentulous & $62,67 \pm 13,23(67)$ & - & $68(60,5)$ & ${ }^{2} 0,463$ \\
\hline
\end{tabular}

${ }^{1}$ Kruskal Wallis Test ${ }^{2}$ Mann-Whitney U Test 
No effect of age and gender on the muscle appearance was found both in each dentate and edentulous when evaluated within each group $(p>0.05)$ (Tables 5 and 6).

\section{DISCUSSION}

In the current study, MM was assessed with ultrasonography as described by Ariji et al., [26]. Systemic diseases, loss of dental structure, pathology and facial musculature pain, age and gender are the factors associated with masticatory performance [12,27 - 29]. Therefore, patients with systemic diseases and muscle pathologies were excluded from our study.

Ultrasonography had been used to measure thickness and evaluate the internal appearance of MM in previous studies and its reliability has already been confirmed [24,30]. Egwu et al. [23] used US for evaluating MM and showed that thickness at rest stage was significantly lower than the contraction stage as same as in our study. However, the cause or mechanism of thickening has not been well described and there could be two possibilities for the increase in thickness. When a muscle is contracted, the muscle fiber filament slides on each other and an increase in fiber diameter cause thickening. Ariji et al. [26] assumed that this changes based on sliding could be observed concomitant with the beginning of contraction. Another reason could be an edematous change of muscle. The thickening of the MM by the clenching of teeth was also confirmed by an experimental study [24].

Table 6. Evaluation of effect of gender on the muscle appearance in groups.

\begin{tabular}{|c|c|c|c|c|}
\hline & \multirow{2}{*}{-} & Female & Male & \multirow[b]{2}{*}{$\mathbf{p}$} \\
\hline & & n (\%) & n (\%) & \\
\hline \multirow{8}{*}{ Dentate } & Right & - & - & - \\
\hline & III & $0(0 \%)$ & $3(25 \%)$ & \multirow{3}{*}{${ }^{1} 0,143$} \\
\hline & II & $4(30,8 \%)$ & $2(16,7 \%)$ & \\
\hline & $\mathbf{I}$ & $9(69,2 \%)$ & $7(58,3 \%)$ & \\
\hline & Left & - & - & - \\
\hline & III & $0(0 \%)$ & $2(16,7 \%)$ & \multirow{3}{*}{${ }^{1} \mathbf{0 , 1 3 3}$} \\
\hline & II & $6(46,2 \%)$ & $2(16,7 \%)$ & \\
\hline & $\mathbf{I}$ & $7(53,8 \%)$ & $8(66,7 \%)$ & \\
\hline \multirow{6}{*}{ Edentulous } & Right & - & - & - \\
\hline & III & $0(0 \%)$ & $2(16,7 \%)$ & \multirow{2}{*}{${ }^{2} 0,478$} \\
\hline & $\mathbf{I}$ & $12(100 \%)$ & $10(83,3 \%)$ & \\
\hline & Left & - & - & - \\
\hline & III & $3(25 \%)$ & $3(25 \%)$ & \multirow{2}{*}{${ }^{2} 1,000$} \\
\hline & $\mathbf{I}$ & $9(75 \%)$ & $9(75 \%)$ & \\
\hline
\end{tabular}

Chi-square Test ${ }^{2}$ Fisher's Exact Test

It was assumed that chewing with removable prostheses might limit the MM thickness. The reasons for this limitation were explained as the perception of displacement or loosening of the denture during unfavourable loading and the discomfort of food getting caught underneath the denture base. Besides, a previous fracture experience of the prosthesis might limit the functional benefit [23,31].

Kubota et al. [32] found that MM thickness as 15.8.0 $\pm 3.0 \mathrm{~mm}$ at rest, and 16.7.0 $\pm 2.7 \mathrm{~mm}$ at contraction in healthy male patients. MM thickness at rest was reported $13.41 \pm 3.09 \mathrm{~mm}$ and at contraction $17.03 \pm 3.50 \mathrm{~mm}$ by Egwu et al. [23] in healthy patients. In their study, Bakke et al. [24] observed that in healthy adults, thickness of the masseter muscle in contraction was strongly correlated with the number of teeth in contact. The study was enrolled in a female subject group and the MM thickness has been found $12.6 \pm 1.8$.

These values are in accordance with the study of Satiroglu et al. [22] who reported MM thickness as $13.56 \pm 1.95$ $\mathrm{mm}$ and $14.57 \pm 1.83 \mathrm{~mm}$ at rest and contraction, respectively in a Turkish subpopulation. Our dentate group findings supported these values through with the slight environmental deviation (11.08 \pm 1.92 at rest and $13.08 \pm 2.08$ at contracted), and with an increased ratio of $13.53 \%$. On the contrary, Liao and Lo. [33] reported relatively lower MM thickness measurements of the patients without TMD as $9.0 \pm 1.9 \mathrm{~mm}$ at rest and $11.8 \pm 2.8 \mathrm{~mm}$ at contraction with an increased ratio of $33 \%$ and they also stated that genders should be considered in clinical judgement for evaluating MM thickness. Ariji et al. [26] stated that MM thickness at rest as $8.28 \pm 1.73 \mathrm{~mm}$ for their healthy group. The increased ratio of 38\% of their study was similar to Liao and Lo's results [33]. Kamala et al. [34] supported these low values with 
$7.75 \pm 0.79 \mathrm{~mm}$ at rest and $10.15 \pm 0.69 \mathrm{~mm}$ at contraction in their healthy control group. Similarly, our edentulous group findings were significantly lower than the dentate group $(9.40 \pm 1.90$ at rest and $10.77 \pm 1.77$ at contracted $)$ with an increased ratio of $14.36 \%$. There was no statistical significance between the increased ratios of edentulous and dentate groups in this study but our ratio values were lower than Ariji et al., [26] and Liao and Lo [33].

None of the previous studies mentioned that whether their patient's groups had been dentate or edentulous. MM thickness values might be effected from the differences of dentition and configuration of the investigated groups eventually. These discrepancies in thickness may also be based on the differences in the measurement methods. For example in the study of Bennington et al., [25], the thickness was measured at the anteroposterior midpoint of the muscle belly. In our study and the previous studies; measurements were performed at the point of estimated maximum thickness of muscle [19, 20]. Bakke et al. [30] also measured the thickness at the anteroposterior midpoint but they estimated the bulkiest level of the muscle. On the other hand, these variations in measurements of different populations may be related with racial perspectives and the relative indulgence in masticatory activities may lead to the tendency of adaptive increase in muscle. It may also be associated with the orientation and size of the muscle fibres that could have genetic and environmental backdrop [23].

Bennington et al. [25] reported that male muscle measurements at contraction tended to be larger than female; (MM thickness at contracted 11.1 $\pm 1.3 \mathrm{~mm}$ and $9.5 \pm 1.2 \mathrm{~mm}$ for males and females respectively). Liao and Lo [33], Egwu et al., [23] and Kiliaridis and Kalebo [20] stated that MM thickness at rest and maximal occlusion was higher in male than female patients. Similarly in our study; dentate group values of MM thicknesses at rest and contraction were also higher in male than female except contracted MM thickness values of left side. But in edentulous group, there was no statistical significance among the genders between MM thicknesses both at rest or contraction stages.

In a comparison study of Müller et al. [31], the lowest chewing performance was found in the conventional complete denture prosthesis group. However, the dentate control-group showed a significantly better masticatory efficiency than all other groups which were implant-supported fixed or removable dental prosthesis. MM thickness was found the thinnest in the conventional complete dental prosthesis group and the thickest in the dentate control-group in the same study. In our study dentate and conventional complete prosthesis, groups were also compared and MM thickness on both right and left side was found significantly larger in a dentate group than edentulous group, supportively. Schimmel et al., [35] also presented a case of a patient who had regained MM thickness after the stabilization of the lower denture with two implants.

An expressive correlation has been shown to exist between age, gender and thickness of the masseter muscle. It has been reported to be greater in men and elderly individuals [21,36]. In a study conducted by Radsheer et al., [19], it was reported that thickness of the masseter muscle decreases with age in both sexes. The similar results were portrayed in studies conducted by Kiliaridis \& Kalebo [20] and Hernandez et al. [37] in relaxed and/or clenched positions of the masseter muscle.

Giving quantitative information about the functional capacity of the muscle, ultrasonography was used to measure the thickness of the masseter muscle [38]. It was reported that the cross-sectional area of the masticatory muscles had reduced in edentulous patients compared with the dentate group regardless of age [10]. Müller et al., [31] confirmed that atrophy of the related muscles could have seen as a result of a prolonged low activity. The reduced radiographic density of the masticatory muscles was also shown with computed tomography, after a long time of wearing conventional complete dentures [20].

The internal ultrasonographic features of the MM were also evaluated in our study and the echogenic echogenicity of bands were detected with less echogenicity (Type III) in an edentulous group than the dentate group. In addition, in our study, there was no statistically significant relationship neither between age and MM thickness nor between age and the band echogenicity of MM. In consideration of the echogenic bands correspond to the internal fascia, tendon or collagen fibers of the muscle; it might be mentioned that in the atrophic muscle these bands tend to quietly diminish or disappear. It is known that the echogenicity on US images are weaker when the differences in impedance between tissues are lesser. As sound waves are reflected from the boundaries between tissues with different acoustic impedance. Thus, in the studies conducted by Ariji et al., [26,39], less echogenicity is suggested to be a consequence of the reduction of the difference in acoustic impedance between tissues which contact each other.

Although the current study demonstrated that MM thickness and muscle echogenicity were significantly different between dentate and edentulous patients, with the conceptual limitations as small sample size. Furthermore; ultrasonography can be used to evaluate the features of MM safely. The internal ultrasonographic features of the 
muscles would lead the clinicians to detect the pathologic state of the muscles. Further studies with larger sample size are needed to detect pathologic changes of the inner structure of masticatory muscles on US views.

\section{CONCLUSION}

In our study, MM thickness at rest and contraction in the dentate group were significantly higher than the edentulous group $(p<0.05)$. Age and gender seemed to have no significant effect on the echogenic type $(p>0.05)$. It was clarified that ultrasonographic features of the MM in dentate and edentulous patients were different. In summary, the results of this study indicate that ultrasonography is a reproducible method for measuring masseter muscle thickness yet there is a need for standardization of methods and parameters to be recorded and future studies with a larger sample are needed for more accurate results.

\section{ETHICS APPROVAL AND CONSENT TO PARTICIPATE}

The study protocol numbered as 09.2015.129 was approved by Non-invasive Clinical Research Ethics Committee, Marmara University Faculty of Medicine.

\section{HUMAN AND ANIMAL RIGHTS}

No animals were used in this research. All research procedures followed were in accordance with the ethical standards of the committee responsible for human experimentation (institutional and national), and with the Helsinki Declaration of 1975, as revised in 2008 (http://www.wma.net/en/20activities/10ethics/10helsinki/).

\section{CONSENT FOR PUBLICATION}

The patients were informed about the study procedure and informed consent was received.

\section{CONFLICT OF INTEREST:}

The authors declare no conflict of interest, financial or otherwise.

\section{ACKNOWLEDGEMENTS}

The authors deny any conflicts of interest. This research was presented in 6. National Symposium and 1. International Congress of ODMFR, İzmir, 2015 and supported by the Marmara University Scientific Research Project Council SAG-E-130213-0022, Project Manager, 2013.

\section{REFERENCES}

[1] Koca-Ceylan G, Taskaya-Yilmaz N, Guler AU, Incesu L, Aksoz T. The effect of unilateral partial edentulism to muscle thickness. Saudi Med J 2003; 24(12): 1352-9. [PMID: 14710283]

[2] Hickey JC, Zarb GA. Boucher's prosthodontic treatment for edentulous patients. In: $8^{\text {th }}$ ed St Louis (MO): CV Mosby 1980; 55: p. 3-11.

[3] Schellhas KP. MR imaging of muscles of mastication. AJR Am J Roentgenol 1989; 153(4): 847-55. [http://dx.doi.org/10.2214/ajr.153.4.847] [PMID: 2773742]

[4] Seltzer SE, Wang AM. Modern imaging of the masseter muscle: Normal anatomy and pathosis on CT and MRI. Oral Surg Oral Med Oral Pathol 1987; 63(5): 622-9.

[http://dx.doi.org/10.1016/0030-4220(87)90241-6] [PMID: 3473385]

[5] Sullivan JD, Olha AE, Rohan I, Schulz J. The properties of skeletal muscle. Orthop Rev 1986; 15(6): $349-63$. [PMID: 3331181]

[6] Hainaut K, Duchateau J. Muscle fatigue, effects of training and disuse. Muscle Nerve 1989; 12(8): 660-9. [http://dx.doi.org/10.1002/mus.880120807] [PMID: 2674709]

[7] Abernethy PJ, Thayer R, Taylor AW. Acute and chronic responses of skeletal muscle to endurance and sprint exercise. A review. Sports Med 1990; 10(6): 365-89.

[http://dx.doi.org/10.2165/00007256-199010060-00004] [PMID: 2291032]

[8] Kiliaridis S, Engström C, Thilander B. Histochemical analysis of masticatory muscle in the growing rat after prolonged alteration in the consistency of the diet. Arch Oral Biol 1988; 33(3): 187-93. [http://dx.doi.org/10.1016/0003-9969(88)90044-1] [PMID: 3178538]

[9] Raustia AM, Salonen MA, Pyhtinen J. Evaluation of masticatory muscles of edentulous patients by computed tomography and electromyography. J Oral Rehabil 1996; 23(1): 11-6. [http://dx.doi.org/10.1111/j.1365-2842.1996.tb00805.x] [PMID: 8850155] 
[10] Newton JP, Yemm R, Abel RW, Menhinick S. Changes in human jaw muscles with age and dental state. Gerodontology 1993; 10(1): 16-22. [http://dx.doi.org/10.1111/j.1741-2358.1993.tb00074.x] [PMID: 8300113]

[11] Newton JP, McManus FC, Menhenick S. Jaw muscles in older overdenture patients. Gerodontology 2004; 21(1): 37-42. [http://dx.doi.org/10.1111/j.1741-2358.2004.00002.x] [PMID: 15074538]

[12] Deniz DA, Kulak Ozkan Y. The influence of occlusion on masticatory performance and satisfaction in complete denture wearers. J Oral Rehabil 2013; 40(2): 91-8.

[http://dx.doi.org/10.1111/joor.12015] [PMID: 23189997]

[13] Suit SR, Gibbs CH, Benz ST. Study of gliding tooth contacts during mastication. J Periodontol 1976; $47(6)$ : $331-4$. [http://dx.doi.org/10.1902/jop.1976.47.6.331] [PMID: 1064720]

[14] Urushiyama T, Akutsu S, Miyazaki J, Fukui T, Diekwisch TG, Yamane A. Change from a hard to soft diet alters the expression of insulin-like growth factors, their receptors, and binding proteins in association with atrophy in adult mouse masseter muscle. Cell Tissue Res 2004 ; 315(1): 97-105. [http://dx.doi.org/10.1007/s00441-003-0787-0] [PMID: 14579143]

[15] Millwood J, Heath MR. Food choice by older people: The use of semi-structured interviews with open and closed questions. Gerodontology $2000 ; 17(1): 25-32$.

[http://dx.doi.org/10.1111/j.1741-2358.2000.00025.x] [PMID: 11203509]

[16] Norton NS. Netter's head and neck anatomy for dentistry. $2^{\text {nd }}$ ed. Muscles of mastication. Philadelphia: WB Saunders 2012; p. 223-5.

[17] Weijs WA, Hillen B. Correlations between the cross-sectional area of the jaw muscles and craniofacial size and shape. Am J Phys Anthropol 1986; 70(4): 423-31.

[http://dx.doi.org/10.1002/ajpa.1330700403] [PMID: 3766712]

[18] Reis Durão AP, Morosolli A, Brown J, Jacobs R. Masseter muscle measurement performed by ultrasound: A systematic review. Dentomaxillofac Radiol 2017; 46(6): 20170052.

[http://dx.doi.org/10.1259/dmfr.20170052] [PMID: 28467130]

[19] Okumuş Ö, Dönmez M, Pekiner FN. Ultrasonographic appearances of cervical lymph nodes in healthy turkish adults subpopulation: Preliminary study. Open Dent J 2017; 11: 404-12. [http://dx.doi.org/10.2174/1874210601711010404] [PMID: 28839488]

[20] Kiliaridis S, Kälebo P. Masseter muscle thickness measured by ultrasonography and its relation to facial morphology. J Dent Res 1991; 70(9): 1262-5.

[http://dx.doi.org/10.1177/00220345910700090601] [PMID: 1918575]

[21] Emshoff R, Emshoff I, Rudisch A, Bertram S. Reliability and temporal variation of masseter muscle thickness measurements utilizing ultrasonography. J Oral Rehabil 2003; 30(12): 1168-72. [http://dx.doi.org/10.1111/j.1365-2842.2003.01186.x] [PMID: 14641658]

[22] Satiroğlu F, Arun T, Işik F. Comparative data on facial morphology and muscle thickness using ultrasonography. Eur J Orthod 2005; 27(6): $562-7$. [http://dx.doi.org/10.1093/ejo/cji052] [PMID: 16135538]

[23] Egwu OA, Njoku CO, Ewunonu EO, Ukoha U, Eteudo AN, Mgbachi CE. Assessment of masseter muscle thickness in an adult nigerian population: An ultrasound based study. Int J Biomed Res 2012; 3: 143-6.

[http://dx.doi.org/10.7439/ijbr.v3i3.304]

[24] Bakke M, Tuxen A, Vilmann P, Jensen BR, Vilmann A, Toft M. Ultrasound image of human masseter muscle related to bite force, electromyography, facial morphology, and occlusal factors. Scand J Dent Res 1992; 100(3): 164-71. [PMID: 1631486]

[25] Benington PCM, Gardener JE, Hunt NP. Masseter muscle volume measured using ultrasonography and its relationship with facial morphology. Eur J Orthod 1999; 21(6): 659-70. [http://dx.doi.org/10.1093/ejo/21.6.659] [PMID: 10665195]

[26] Ariji Y, Sakuma S, Izumi M, et al. Ultrasonographic features of the masseter muscle in female patients with temporomandibular disorder associated with myofascial pain. Oral Surg Oral Med Oral Pathol Oral Radiol Endod 2004; 98(3): 337-41. [http://dx.doi.org/10.1016/j.tripleo.2004.06.068] [PMID: 15356473]

[27] Galo R, Vitti M, Santos CM, Hallak JE, Regalo SC. The effect of age on the function of the masticatory system--an electromyographical analysis. Gerodontology 2006; 23(3): 177-82. [http://dx.doi.org/10.1111/j.1741-2358.2006.00113.x] [PMID: 16919099]

[28] Hatch JP, Shinkai RS, Sakai S, Rugh JD, Paunovich ED. Determinants of masticatory performance in dentate adults. Arch Oral Biol 2001; 46(7): 641-8. [http://dx.doi.org/10.1016/S0003-9969(01)00023-1] [PMID: 11369319]

[29] Galo R, Vitti M, Mattos MdaG, Regalo SC. Masticatory muscular activation in elderly individuals during chewing. Gerodontology 2007; 24(4): 244-8.

[http://dx.doi.org/10.1111/j.1741-2358.2007.00170.x] [PMID: 17999738] 
[30] Kiliaridis S, Van Eijden TM, Van Ginkel FC, Prahl-Andersen B. Masseter muscle thickness in growing individuals and its relationship to facial morphology. Arch Oral Biol 1996; 41: 323-32.

[http://dx.doi.org/10.1016/0003-9969(95)00136-0] [PMID: 8771323]

[31] Hernandez M, Grütter L, Aracil-Kessler L, Weingart D, Schimmel M. Masseter muscle thickness, chewing efficiency and bite force in edentulous patients with fixed and removable implant-supported prosthesis: A cross sectional multicenter study. Clin Oral Implants Res 2012; 23: 144-50.

[http://dx.doi.org/10.1111/j.1600-0501.2011.02213.x] [PMID: 21631592]

[32] Kubota M, Nakano H, Sanjo I, et al. Maxillofacial morphology and masseter muscle thickness in adults. Eur J Orthod 1998; $20(5)$ : 535-42. [http://dx.doi.org/10.1093/ejo/20.5.535] [PMID: 9825556]

[33] Liao LJ, Lo WC. High-resolution sonographic measurement of normal temporomandibular joint and masseter muscle. J Med Ultrasound 2012; 20: 96-100 [http://dx.doi.org/10.1016/j.jmu.2012.04.003]

[34] Kamala KA, Annigeri RG, Ashok L. Ultrasonic diagnosis of masseteric hypertrophy in oral submucous fibrosis: A prelimnary study. J Ind Academy Oral Med Radiol 2010; 22: 194-200.

[35] Schimmel M, Loup A, Duvernay E, Gaydarov N, Muller F. The effect of mandibular denture abstention on masseter muscle thickness in a 97year-old patient: A case report. Int J Prosthodont 2010; 23(5): 418-20. [PMID: 20859556]

[36] Rohila AK, Sharma VP, Shrivastav PK, Nagar A, Singh GP. An ultrasonographic evaluation of masseter muscle thickness in different dentofacial patterns. Indian J Dent Res 2012; 23(6): 726-31. [http://dx.doi.org/10.4103/0970-9290.111247] [PMID: 23649053]

[37] Hernandez CA, Frugone ZR, Valenzuela PH, Retamal VV. Masseter muscle deep measured by ultrasound per facial index related to sex. Int J Morphol 2012; 30: 964-9.

[38] Lione R, Kiliaridis S, Noviello A, Franchi L, Antonarakis GS, Cozza P. Evaluation of masseter muscles in relation to treatment with removable bite-blocks in dolichofacial growing subjects: A prospective controlled study. Am J Orthod Dentofacial Orthop 2017; 151(6): 1058-64.

[http://dx.doi.org/10.1016/j.ajodo.2016.10.035] [PMID: 28554451]

[39] Ariji Y, Nakayama M, Nishiyama W, et al. Can sonographic features be efficacy predictors of robotic massage treatment for masseter and temporal muscle in patients with temporomandibular disorder with myofascial pain? Cranio 2016; 34(1): 13-9.

[http://dx.doi.org/10.1179/2151090314Y.0000000037] [PMID: 25399824]

\section{(C) 2018 Mayil et al.}

This is an open access article distributed under the terms of the Creative Commons Attribution 4.0 International Public License (CC-BY 4.0), a copy of which is available at: (https://creativecommons.org/licenses/by/4.0/legalcode). This license permits unrestricted use, distribution, and reproduction in any medium, provided the original author and source are credited. 